\title{
LA NOVELA CORTA EN FUNCIÓN EDUCATIVA: LEYENDO A ROSE MARIE TAPIA Y SU PRESENCIA EN EL GÉNERO
}

\author{
Humberto López Cruz \\ University of Central Florida \\ hlopez@ucf.edu
}

Resumen: La novela corta es un subgénero que no ha encontrado en español el desarrollo tradicional que sí ha disfrutado la clasificación que la supera por extensión; es decir, la novela. En el caso de la escritora panameña Rose Marie Tapia, la novela corta es la que se destaca en la mayoría de sus relatos; sus entregas reflejan la brevedad requerida por el subgénero que presenta. Este trabajo se aproxima a dos de sus entregas con especial énfasis en un texto que educa por medio de una prosa que se renueva; novelas cortas que se convierten en instrumentos discursivos que fungen como agentes transmisores de una idea, un concepto, un propósito, y en los que la brevedad de la escritura acentúa la magnitud de los relatos.

Palabras clave: Rose Marie Tapia, literatura panameña, discurso didáctico, novela corta

\section{THE NOVELLA IN ITS EDUCATIONAL FORM: READING ROSE MARIE TAPIA AND HER PRESENCE IN THE GENRE}

\begin{abstract}
The novella is a subgenre that has not found in Spanish language the traditional development that has enjoyed the classification that surpasses it by extension; that is, the novel. In the case of the Panamanian writer Rose Marie Tapia, the novella is the one that stands out in the majority of her stories; her deliveries reflect the brevity required by the subgenre she presents. This essay approaches two of her works with special emphasis on a text that educates through a prose that renews itself; novellas that become discursive instruments that act as transmitting agents of an idea, a concept, a purpose, and in which the shortness of the writing accentuates the magnitude of the stories.
\end{abstract}

Keywords: Rose Marie Tapia, Panamanian literature, didactic discourse, novella

DOI: https://doi.org/10.24029/lejana.2020.13.264

Recibido: el 2 de noviembre de 2018

Aceptado: el 1 de marzo de 2019

Publicado: el 19 de febrero de 2020 


\section{La literatura aborda la historia anónima \\ $-y$ con frecuencia silenciada \\ — de las comunidades sin voz oficial.}

La literatura es el gran espejo del acontecer humano.

(Ríos Torres)

La novela corta es un género, imposible ya denominarlo subgénero, que no ha encontrado en español el desarrollo tradicional que sí ha disfrutado la clasificación que la supera por extensión; es decir, la novela. Pese a este hado negativo, la novela corta o noveleta, como la suelen llamar en algunos círculos literarios, no está completamente desaparecida de las letras del mundo hispano, muy por el contrario. Walter Pabst rastrea la entidad de la novela corta en las letras hispanas desde la Edad Media y recoge que "la autoridad del dogma era tan grande, que los autores de las novelas cortas no pudieron pasar de largo junto a él sin prestarle atención, y muchos de ellos tomaron posición frente a la teoría, principalmente en prólogos, introducciones y relatos secundarios" (1972: 18). La importancia y la presencia han sido notables, aunque la mirada crítica observase en otra dirección; las aproximaciones de estudio tendrían que ir privilegiando un procedimiento evaluativo que colocase el estilo, a falta de mejor vocablo, en el lugar adecuado.

Numerosos han sido los escritores que han cultivado el género; si fuere necesario apuntar un ejemplo canónico habría entonces que mencionar a Miguel de Cervantes como pilar irrefutable de esta peculiar narración; a su vez, habría que añadir que jamás la brevedad impidió un intenso desenvolvimiento textual que sirvió, y sigue sirviendo, como difusión didáctica para beneficio del lector del momento. Agustín de Amezúa y Mayo declara a Cervantes como creador del género tras la publicación de las imprescindibles Novelas Ejemplares cervantinas. El estudioso sostiene que "Cervantes siente algo nuevo en él: el deseo, la comezón de escribir novelas cortas, y seguro y confiado en sí mismo, se resuelve a entrar por esta nueva vía, apenas hollada por nadie antes que él, e impulsado por su temperamento estético, encaminado hacia una tierra dilatadísima y feraz donde campear por sus anchas" (1982: 415). ${ }^{1}$ La necesidad de narrar siendo breve se impone.

Este último punto es esencial a la hora de entender por qué narradores contemporáneos favorecen recurrir a la novela corta como alocución y no como casualidad creativa. Las entregas se convierten en instrumentos discursivos que fungen como agentes transmisores de una idea, un concepto, un propósito, y en los que la brevedad de los textos acentúa la intensidad de los relatos; en otras palabras, los autores necesitan sumergirse de lleno, y con rapidez, en la trama porque la extensión esperada del texto no permite divagaciones alternas. Por su parte, los lectores tienen ante sí una narración con un propósito que tiene que cumplirse y entenderse, entre prólogo y epílogo; o sea, que el reto es para ambos: uno tiene que exponer y el otro tiene que entender. No siempre se estará de acuerdo, pero sí habrá que admitir que la

\footnotetext{
${ }^{1}$ Los lectores deberán consultar, en su totalidad, el capítulo IX del texto de Amezúa y Mayo, "Caminos hacia la novela corta" (1982: 396-415) para lograr una mejor comprensión de su postura crítica ante el género y el papel fundamental desempeñado por Cervantes. Obsérvese que este apartado abre puertas a subsecuentes lecturas que serían de ayuda para aquellos interesados en continuar rastreando el tema. El estudio, pese a los años de haber sido publicado, no pierde actualidad.
} 
longitud de lo expuesto no es un factor a modificar; no hay negociación posible en lo que respecta al número de páginas. De otra forma, no sería una novela corta.

Tras este preludio informativo, es hora de comentar la obra narrativa de una escritora panameña contemporánea que, durante las últimas dos décadas, ha visto su incursión en las letras aumentar hasta situarse en un notable lugar dentro de los círculos literarios del istmo. Rose Marie Tapia (1947-) caracteriza sus publicaciones por la longitud de sus relatos. ${ }^{2}$ En su mayoría, la novela corta es la que se destaca del resto; sus entregas reflejan la brevedad requerida por el género que despliega. Este trabajo se aproxima a dos de sus entregas con especial énfasis en un texto que educa, por medio de una prosa que se renueva, tras cada escritura.

Si se aceptara esta información como válida, y no parece haber razón convincente para ejercer una duda sólida en contra de dichos postulados, el resto sería ubicar la trama dentro del propósito orientado a la enseñanza que aspira satisfacer. La autora es consciente de estas premisas y elabora unos textos que tienen que capturar a sus lectores para que triunfe la labor educativa. Las novelas escogidas, y no que otras carezcan de la intensidad requerida para amparar estos razonamientos, son Niña bella (2010) y Diagnóstico N.P.I. (2011). Ambas cuentan con menos de cien páginas y, desde el comienzo, se percibe la función educativa que ya caracteriza las letras de Tapia. En una interesante propuesta, Manuela Merino García destaca que la novela corta merece especial atención (pese a que el estudio se ha basado en letras de otras épocas es factible hacerlo extensivo al género en particular), "pues con su verosimilitud y su elección de temas contemporáneos sedujo al público francés y contribuyó a la renovación de la técnica narrativa" (2005: 6). Este aserto es necesario para ubicar la narrativa presentada.

Ambos textos se acercan en puntos que conviene resaltar. Por ejemplo, el lector conversa con voces autorizadas que llevan la palabra de la autora dentro de una ficción que se resiste a abandonar la realidad que la rodea. Este conflicto parece solucionarse por medio de una lectura que acepta la trama propuesta y que se fusiona con discurso didáctico para, junto a ella, alcanzar un fin común. En Diagnóstico, la presencia autorial se impone dentro de un antagonismo que varía entre resignación ante lo inexorable y posible denuncia social del gremio médico. En Niña Bella, la exposición oscila entre una narrativa omnisciente y una voz en primera persona que trasciende la imparcialidad — nunca es percibida como tal - de la tercera persona. Pese a ello, en las dos novelas destaca el propósito pedagógico que subyace en el entramado textual, superando, a veces, el desarrollo de la supuesta ficción; es muy posible que Tapia, conscientemente, eligiera la novela corta como vehículo de difusión de su mensaje educativo.

Visto esto, hay que traer a colación el compendio crítico de Anadeli Bencomo y Cecilia Eudave para apuntalar estos acercamientos a las dos entregas de Tapia. Para

\footnotetext{
${ }^{2}$ Al momento de redactar estas líneas, Rose Marie Tapia lleva publicadas, en Panamá, las siguientes novelas: Caminos y encuentros (2000), Y era lo que nadie creía (2001), Travesías mágicas (2002), La noche oscura (2002), La cárcel del temor (2003), Roberto por el buen camino (2003), La raíz de la hoguera (2005), Los ángeles del olvido (2006), No hay trato (2007), Mujeres en fuga (2008), Agenda para el desastre (2009), Niña bella (2010), El retorno de los bárbaros (2010), El crepitar de la hoguera (2011), Diagnóstico N.P.I. (2011), Los misterios del olvido (2012), El arcoíris sobre el pantano (2013), El poder desenmascara (2014), Un grito desde el silencio (2015), El murmullo de la sombra (2016), Vida de compromiso (2017), La noche no dura para siempre (2018). Como puede verse, Tapia ha estado muy activa en su labor de creación literaria.
} 
comenzar, es imperioso partir de que "la interrogante acerca de la especificidad de la novela corta conduce igualmente a las reflexiones sobre la naturaleza del relato que se recoge de sus páginas", y así continuar con que "es importante señalar además que este proceso recogido en el relato se representa generalmente como algo que ha comenzado antes de iniciar la narración propiamente dicha" (2014: 12-13). Como colofón a estas citas, hay que agregar que los lectores ya están prevenidos y esperan, no un mensaje fabulístico, sino una reproducción de hechos tangibles que se aplique a su realidad cotidiana. Dicho de otra forma, son escenas sociales que se novelan para ambientar tramas que van a buscar soluciones, o prevenciones, de temas que, de otra forma, no se hubiesen enfrentado. Las reflexiones van a transmutar de personaje a lector salpicadas por el ingenio de la autora, de esta sagacidad narrativa es que se tendrá que valer la escritura si desea lograr el éxito propuesto. En este momento sería apropiado iniciar un escudriñamiento de las novelas seleccionadas para afirmar o desmentir la intención de este ensayo.

La elección sobre el estilo narrativo en ambas narraciones, ya observado con anterioridad, sugiere la importancia de unos discursos textuales que van a superar las tramas. Tapia es consciente del arbitrio ya que ese sería un logro de su decisión de trabajar la novela corta; además, se impondría la función educativa ante el posible entretenimiento que conllevaría cualquier lectura. En otras palabras, aquí se accede al mensaje educativo, puesto que, como fábula novelada, se anticipa que la lectura subrayará el aprendizaje, y cualquiera que la enfrente se concentrará más en el enunciado narrativo que en el desarrollo de sus personajes. Este último punto es uno a considerar: la brevedad del texto impide un desarrollo exhaustivo de personajes que entran a cumplir un propósito determinado; no es necesario hacer énfasis en el desenvolvimiento de los protagonistas, sino en la virtud que representan o problemática que encaran. En la conclusión de los relatos, es la voz de Tapia la que impone la moraleja (puede decirse que la lección ha logrado una feliz intersección con el entendimiento de los lectores), y cumple con lo que se espera de sus entregas. A su vez, y como nota adicional, posibilita la gestación de un reto dirigido, no al lector promedio, sino al espacio en que se desenvuelven; una crítica social dice presente.

Es necesario pausar y acercar este estudio a otra de las novelas de Tapia, Roberto por el buen camino, que aunque no haya sido incluida como parte de este ensayo, se considera una de las más vendidas en Panamá, a más de que fuera traducida al inglés como Roberto Down the Right Path. ${ }^{3}$ Sin embargo, lo que hay que destacar son las conclusiones de Sara Wiercinski sobre la novela aludida, pues, según la estudiosa, la escritora panameña retrata la escasez imperante y enfrenta a los lectores con las duras condiciones de vida que afectan a las comunidades pobres, demostrando que la falta de recursos y el abandono de la niñez son las principales fuentes de delincuencia juvenil (2013: 183). Tapia proyecta, a lo largo de los capítulos y con la crudeza que se espera del tema, ejemplos orientados a formular su denuncia textual; la novela corta educa y critica sectores sociales que, desde el punto de vista de la autora, lo merecen. Wiercinski concluye con que "el mensaje principal es claro y conmovedor", para subrayar que el protagonista y "el grupo de delincuentes juveniles son víctimas de la desigualdad social manifestada en la sociedad" (183, la traducción es mía). El

\footnotetext{
${ }^{3}$ Roberto Down the Right Path fue publicada en Panamá por la Editorial L \& I, en 2010. La traducción corrió a cargo de Pat Alvarado. No incluyo esta ficha en las obras citadas por no ser, la novela, parte de este estudio. Sin embargo, el curioso lector ya sabe cómo acceder al texto en caso de que fuere de su interés.
} 
antihéroe ha sido trasmutado en héroe, en realidad nunca dejó de serlo ante los ojos de los lectores, y la autora ha dado voz a un estrato nacional marginado como parte del proceso educativo.

Una proyección similar se detecta en las lecturas de Diagnóstico N.P.I. y Niña Bella. En la primera novela seleccionada, y al enfrentar la escritura, comienza el proceso de aprendizaje; más bien, es la oportunidad para canalizar las opciones que tiene el individuo promedio a la hora de encarar un diagnóstico médico. Tapia no propone, como fuera apuntado con anterioridad, un cuestionamiento a la totalidad médica, pero sí la obligación de cada paciente de documentarse antes de aceptar un tratamiento o una posible receta. La reacción negativa que sufre la protagonista ante un conocido fármaco, posiblemente producto de un diagnóstico errado, es la enseñanza que se debe extraer, ya que "los efectos colaterales de los medicamentos fueron enormes" (2011: 64); además, hay una aprensión sobre uno en particular, puesto que "provocaba hemorragias" (65). La autora es explícita, en completa función educativa, a la hora de subrayar los productos por su nombre, afianzando, de este modo, el aprendizaje que reciben los lectores al convertirse el texto, entiéndase la novela corta, en material didáctico. Hay que aceptar que en algunos círculos sociales, la ciudadanía promedio no se permite a sí misma dudar de un diagnóstico médico, y, Tapia, desde la burla del título escogido, hace caso omiso de este respeto perpetuo para alertar, a través de la protagonista, de las consecuencias de no asumir su responsabilidad social.

El también escritor panameño, Ariel Barría Alvarado, ${ }^{4}$ concede, al referirse al enunciado educativo que ofrece Diagnóstico que "el conocimiento pasa por una estación ineludible; la que nos hace reconocer que necesitamos saber, que requerimos aprender" (contraportada); sin embargo, valdría agregar que la trama de la novela avanza un paso más al empoderar a un colectivo determinado que no va a aceptar a ciegas un diagnóstico médico; de hecho, lo va a cuestionar y, si fuere necesario, buscaría opciones alternas tal y como hizo la protagonista (66-68). Esto nos lleva a la afirmación de Bencomo y Eudave cuando exponen que "se trata entonces de entender que el relato dentro de la novela corta no debe leerse exclusivamente de manera horizontal, sino verticalmente y entre líneas, a partir de los pliegues y disonancias del discurso, y sobre los posibles titubeos del narrador" (2014: 13). En la novela que se discute, la narración en primera persona titubea ligeramente antes de afirmarse en su propia responsabilidad como paciente y como elemento social; el discurso, entonces, adquiere una asonancia figurativa que compagina con el propósito pedagógico de un texto que Tapia no abandona.

Por otra parte, Niña Bella, sigue la tradición educativa pero no con la misma agresividad vista en Diagnóstico. En este punto cabría la opción de comentar otro alegato sobre el tema presentado pues "es en este sentido que la novela corta se muestra como una obra particularmente propicia para llevar a cabo una lectura atenta del texto, una práctica que nos invita a recorrerlo sin mayores prisas o atajos, que nos conduce incluso a la relectura como manera idónea de aproximación crítica" (Bencomo y Eudave, 2014: 13). La novela afirma su testimonio en la realidad de la crisis económica internacional experimentada por todos, o casi todos, los sectores sociales y "nos muestra cómo es posible encender nuestra luz

\footnotetext{
${ }^{4}$ Ariel Barría Alvarado, novelista y cuentista panameño contemporáneo, suele escribir las contraportadas de las novelas de Tapia. En estos breves textos se puede observar la tendencia de Barría Alvarado de recomendar dichas novelas, entre otros motivos no menos significativos, por el aprendizaje que se desprende de sus lecturas.
} 
interior para salir adelante, aun cuando las amenazas parezcan cerrarnos el paso" (Barría Alvarado, 2010: contraportada). Tapia deposita la atención referida por Bencomo y Eudave en un joven personaje, protagonista del relato. Este punto es significativo; se inviste a la denominada niña con características no comunes en alguien de su edad, pero lo más importante es que se transfiere el mensaje educativo a la nueva generación; la voz narrativa en primera persona apoya la finalidad discursiva. La autora logra incluir al ciudadano promedio, acierto constante en sus letras, para que su novela corta afronte un problema común y ofrezca soluciones de cómo solventarlo; este es el encargado de zanjar la crisis transmutada de internacional a personal. El personaje indica en la consumación del relato que "ahora cuando se acuesta, no solo lo hace para descansar, sino también para soñar, pues tiene la capacidad y la fuerza necesarias para cumplir sus propósitos. Ha desarrollado un sentido de su propio destino, un sentido de su visión y de su papel singular en la vida: un sentido de propósito y significado" (2010: 100). Esta conclusión hace reflexionar y rememorar las observaciones de Jorge Volpi cuando sugiere que "la narrativa hispanoamericana ha dejado de existir como un corpus uniforme", para continuar con que "los narradores hispanoamericanos han dejado de escribir sobre los mismos temas" (2008: 109). Tapia es un buen ejemplo; la autora se autoincluye en el conjunto escritural que aduce Volpi para avalar su postura educativa: ha abandonado temas recurrentes en las letras de la región para adentrarse en nuevas avenidas discursivas sonde la novela corta parece ser su mejor aliado.

La conclusión de Diagnóstico es más directa; esto es, la voz autorial supera al personaje y se dirige directamente al lector: "si usted padece una enfermedad sin diagnóstico, no permita que muera la esperanza, y cuando las sombras invadan su corazón, siga buscando, pues detrás de esa sombra está la esperanza y, sosteniéndola, se encuentra la fe" (92-93). Es cierto que este mensaje se puede tildar de sutileza espiritual o como una traviesa asechanza destinada al lector; no obstante, tal como se indicara en una cita previa, los relatos han generado una reflexión ulterior que posiciona al novelista de turno, en este caso a Tapia, en una posición privilegiada con respecto a la escritura: el tema escogido ha superado la tradición literaria de la región y se inscribe en las letras istmeñas con sus propias coordenadas; las palabras de Volpi respaldan estas conclusiones. Es una lectura que está al alcance del individuo promedio que, desde esta plataforma, asume una postura activa y cuestiona, tal como la autora reclama, todo lo que afecte su espacio en la sociedad de la que, desde siempre, es parte. Es acertado decir que Tapia cumple su propósito; además, hay que añadir que el haber escogido el género de la novela corta contribuye al éxito del discurso educativo.

\section{Bibliografía}

AMEZÚA Y MAYO, Agustín G. de (1982): Cervantes. Creador de la novela corta española. Vol. 1. Madrid, Consejo Superior de Investigaciones Científicas. [1956].

BARRÍA ALVARADO, Ariel (2010): "Niña Bella". Niña Bella. Por Rose Marie Tapia. Panamá, Distribuidora Lewis, contraportada.

--- (2011): “Diagnóstico: N. P. I.”. Diagnóstico: N. P. I. Por Rose Marie Tapia. Panamá, Distribuidora Lewis, contraportada. 
BENCOMO, Anadeli y Cecilia Eudave (2014): “Presentación”. En Anadeli Bencomo y Cecilia Eudave (eds.), En breve: la novela corta en México. Guadalajara, México, Universidad de Guadalajara: 11-14.

MERINO GARCÍA, María Manuela (2005): "La recepción de la novela corta española en Francia: Sorel y Scarron”. Transitions. Journal of Franco-Iberian Studies 1 (2005): 619.

PABST, Walter (1972): La novela corta en la teoría y en la creación literaria. Trad. Rafael de la Vega. Madrid, Gredos. [1967].

RÍOS TORRES, Ricardo Arturo (2008): Memoria de mis memorias. Panamá, Círculo de Lectura Guillermo Andreve.

TAPIA, Rose Marie (2010): Niña Bella. Panamá, Distribuidora Lewis.

--- (2011): Diagnóstico: N.P.I. Panamá, Distribuidora Lewis.

VOLPI, Jorge (2008): “Narrativa hispanoamericana, Inc.”. En Jesús Montoya Juárez y Ángel Esteban (eds.), Entre lo local y lo global. La narrativa latinoamericana en el cambio de siglo (1990-2006). Madrid/Frankfurt, Iberoamericana/Vervuert: 99-112. DOI: https://doi.org/10.31819/9783865278227-007

WIERCINSKI, Sara (2013): "Scapegoat, Criminal and Hero: The Lives of Young Offenders in Rose Marie Tapia's Roberto Down the Right Path". En Will Wright y Steven Kaplan (eds. e Introducción), The Image of the Outsider in Literature, Media, and Society III. Pueblo, University Press de Colorado: 177-84.

(C) Humberto López Cruz

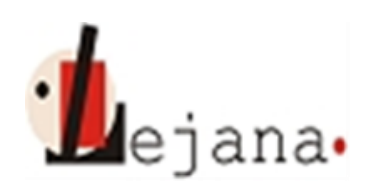

http://ojs.elte.hu/index.php/lejana

Universidad Eötvös Loránd, Departamento de Español, 1088 Budapest, Múzeum krt. 4/C 